The bold items in the margin describe the subject matter and are keywords for text retrieval. The final reference number under each abstract is also used for this purpose (see reprint service on $p .$.

\section{CRM}

\section{Abstracts}

Each abstracted article is awarded 0-5 stars for each of four qualities:

(1) depth of research

(2) value in practice

(3) originality of thinking

(4) readability for non-specialists.

No abstract is included for any article awarded less than seven stars overall.

\title{
Monitoring qualitative aspects of CRM implementation: The essential dimension of management responsibility for employee involvement and acceptance
}

\section{Corner and B. Rogers}

DISCURSIVE. Journal of Targeting, Measurement and Analysis for

Marketing (UK), Vol. 13, No. 3, p. 267 (8pp)

Notes CRM's reputation for great potential but poor track record. Sets out to describe the characteristics of 'good' CRM systems observed by the authors, compared with those of 'inadequate' CRM systems. Notes 12 characteristics of good systems, and holds that any system that cannot claim at least eight or nine of these characteristics must be inadequate. Holds that, at a technological level, CRM software systems must be reasonably competent, and that expensive implementations are usually carefully planned and monitored by competent staff. Holds therefore that the fault lies in the adoption by default of a number of invalid assumptions about human behaviour: that people will accept new methods because the benefits have been explained to them; that people will prioritise the organisation's interests over their own, and over those of their departments; that different functions share a common view of the organisation's best interests. Insists that the reverse is true. Advises 'asking' not 'telling' staff, and outlines modes of consultation.

Recommends risk assessment, allowance for budget overrun and withholding of a sum for last-minute adjustments to the system. Holds that users must 'own' the system, and that skilled analysis and management of people are an essential element of success, alongside technology and the management of business processes and metrics.

Impossible to fault this thesis: anyone who has ever tried to replace a working manual system with a computer-based alternative is aware (sometimes painfully) of these human problems. Which is not to say that technology and process management are not, at least as frequently, at fault.

Research: — Practice: $* * \quad$ Originality: $* * \quad$ Readability: $* * *$ 


\section{Advertising, adtracking, retail, menswear}

\section{Retail, geographical analysis, GIS, modelling}

\section{Breaking from convention: Bringing rigour to retail adtracking}

T. Denison

CASE STUDY. Journal of Targeting, Measurement and Analysis for Marketing (UK), Vol. 13, No. 3, p. 234 (5pp)

Explains the efforts of Slater Menswear in Glasgow (the world's largest single menswear store) to find a new and more accurate way to measure advertising effectiveness. Notes the ineffectiveness of changes in sales volumes as a measure; claims that conventional adtracking through ad recall is inadequate, and that, as practised over the last 30 years, often leads to recall of the ad rather than the product or the seller. Reveals that exit surveys proved useless, and that eventually the company settled upon changes in store footfall as the most appropriate metric. Notes the difficulties involved in measuring this, including the need to identify shopper groups rather than just individuals. Quotes the company as saying it has found a UK company able to solve these problems with 95 per cent accuracy via an electronic customer-counting system. Claims that such systems, while not new, have been slow to gain acceptance, since early versions were inadequate; the industry now has access to 'secondgeneration' systems. Shows an example graph tracking weekly store traffic against overall high-street traffic (using SPSL's Retail Traffic Index), superimposed on a time series of $\mathrm{TV}$, radio and window-display advertising.

A refreshingly direct approach to making another area of advertising accountable; sadly short on nitty-gritty methodology, however.

Research: $* * \quad$ Practice: $* * *$ Originality: $* * *$ Readability: $* * * *$ Ref: 7202

\section{Retail network planning - Achieving competitive advantage through geographical analysis \\ A. Thompson and J. Walker \\ EXPLORATORY. Journal of Targeting, Measurement and Analysis for Marketing (UK), Vol. 13, No. 3, p. 250 (8pp)}

Notes growing interest in geographical analysis techniques such as GIS; holds that the importance now for competitive advantage is not whether one has such a capability, but the quality of the models and analysis applied. Gives a table of typical uses for geographical analysis in nine different markets. Suggests a series of sample questions that geographical analysis might be equipped to answer. Considers the types of external data required for such analysis: zone boundary data; Census data; population data; geodemographics; lifestyle data; propensity data; contextual data; competitor locations; customer and business data. Discusses each. Discusses software tools. Lists and discusses types of forecasting models, with pros and cons of each: analogue models, multiple regression models and gravity models, with the last-named doing best - particularly in relation to interactions of proposed and existing outlets - but also being the most difficult to implement. Summarises the advantages of this general approach. 


\section{Direct marketing, data hygiene, accuracy, address management, ID cards}

\section{CRM, relationship marketing, financial services, direct marketing}

A quick and useful run-through of the various approaches to geographical analysis - with specific reference to the retail trade, but with broader implications as well.

Research: $* * \quad$ Practice: $* * *$ Originality: $* * \quad$ Readability: $* * * *$ Ref: 7203

\section{The future of direct marketing: Accuracy counts Anon \\ JouRnAlistiC. DM Business (UK), Vol. 7, No. 2, p. 12 (5pp)}

Notes the publication's continuing campaign for data hygiene, better targeting and less waste, and considers how far this might bear fruit by 2012. Notes the current consumer campaign against Victoria's Secret in the USA, which mails 395 million catalogues per year. Refers to the UK DMA's Planet Ark campaign to reduce wastage. Draws attention to the opportunities for identity fraud. Emphasises the need for accurate data recording and deduplication services: notes the availability of address management services via the internet. Suggests that the market for address management requires speed of service and ease of use. Considers a scenario in which individual identification will no longer be via a name and address (rendering current problems in address handling, of which some are insuperable, irrelevant) but through a single personal identifier, perhaps related to an ID card, usable through all channels. Notes the opportunities that the introduction of ID cards would present to data management specialists, but concludes that in the meantime the need for a single unique view of each customer in a properly deduplicated database is paramount.

An easy read, rehearsing some familiar problems of data handling which are still not sufficiently understood at a senior level in data-owning companies.

Research: * Practice: $* * \quad$ Originality: $* \quad$ Readability: $* * *$ Ref: 7204

\section{For many companies 'customer driven marketing' is no longer a vision, but also a headache. Why? \\ J. Epstein \\ DISCURSIVE (Editorial). Journal of Financial Services Marketing (UK), Vol. 9, No. 4, p. 303 (4pp)}

Queries whether financial services marketers are doing a better job than was the case ten to 15 years ago, following all the customer-focused innovations. Notes the promise of 'relationship marketing', and its difficult, lengthy and expensive implementation, accompanied by organisational upheavals and erosion of investor confidence. Alleges that several organisations have recently made U-turns in customer investment, whose promises ceased to be believed - due to poor execution. Decries the technology-led approach repeatedly used, and demands a 'customertested' approach to deliver actionable learning before starting serious 
Motor insurance, CRM, customer satisfaction investment. Complains of the lack of understanding of basic principles of direct marketing - often falsely regarded as a tactical activity — which have been known to direct marketers for years, but forgotten in the rise of the 'customer movement'. Suggests that DM skills have been fragmented into separate, specialist areas, leading to an erosion of core knowledge, less rigour, less insight, less innovation and exploitation of the opportunities available through direct channels. Notes the tendency for companies either to locate call centres overseas or to move to non-human points of contact with customers as methods of reducing costs. Observes that data are increasingly used to power non-human contacts instead of the much more productive human contacts.

The author does that rare thing: he writes from his personal experience as a customer, and tells it like it is. This is not a research-based paper, nor chock-full of answers to daily problems - but it describes well the basis of some of those problems.

Research: —— Practice: $* * * *$ Originality: *** Readability: ***** Ref: 7205

\section{How the automotive insurance claims experience affects customer retention}

\section{A. Bond and M. Stone}

RESEARCH. Journal of Financial Services Marketing (UK), Vol. 9, No. 2, p. 160 (12pp)

Points out that the motor insurance business has focused, for 20 years, almost entirely on price, and has managed its claims process entirely separately from CRM. Relates the creation of a 300-person telephone questionnaire designed to determine customers' experience of the claims process, and their relevant attitudes, followed by in-depth face-to-face interviews with senior insurance brokers and major resellers. Shows tables indicating how motorists buy insurance, and what proportions shop around at renewal. Notes that, because call centres are measured on volume, customers are not talked through policy benefits. Claims that after a claim, customers become more proactive about renewal, challenging price and cover. Notes that it takes three to seven years for a policyholder to become profitable, and that 53 per cent of respondents reported no loyalty to their insurer, this figure being lower among claimants than non-claimants. Gives tables showing the state of customers' stated relationships with their insurers; top customer requirements; other requirements; how these divide between claimants and non-claimants; attitudes to and experience of the claims process; experience of a replacement car; willingness to pay more for an excellent service. Concludes that customers now know what they are paying, but not what they are buying: ends with recommendations for insurers.

An interesting study of a purely price-led service. But whether what customers say they would do would be borne out in practice must be open to query. 
Research: $* * *$ Practice: $* * *$ Originality: $* *$ Readability: $* * *$ Ref: 7206

\section{Acquisition, prospects, electoral register, modelling, multi-sourcing}

\section{Privacy, consumerism, EMM}

\section{The case for multi-sourcing prospect pool data}

J. Berry and P. Rowson

EXPLORATORY. Journal of Database Marketing and Customer Strategy Management (UK), Vol. 12, No. 3, p. 207 (5pp)

Notes a shift among B2C companies engaged in large-scale recruitment from ad hoc list purchase towards developing prospect pools. Gives reasons: reduced cost through bulk purchase; ease in generating mass campaigns; low cost of electoral roll; availability of add-on data; effectiveness of predictive models; reduced IT costs; ability to amalgamate customer and prospect data; ability to manage long-term contact strategy. Suggests minimum DM spend for such an approach is $£ 5 \mathrm{~m}$ per year. Notes that since the introduction of electoral roll opt-outs, there is a significant variation in the names produced from the ER by different suppliers. Finds that, out of every 100 unique names obtained from two ER suppliers and one non-ER supplier, no supplier provided more than 75 per cent of the total: ie multi-sourcing provided one-third more names. Shows how a response model, applied to the names from each source separately, to each combination of two sources and to a combination of three sources, produces much better results as the number of sources increases. Looks at cost implications: the average prospect pool contains 12 million records and 370 fields, and produces an average of 14 million mailings. Concludes that the main benefits of multisourcing come from increased footprint and better targeting; the costs from extra data and data processing.

A short, succinct account; the variation in ER names between suppliers may be somewhat startling to those who have not experienced it.

Research: $* *$ Practice: $* * * *$ Originality: $* * * *$ Readability: $* * * *$ Ref: 7207

\section{The rise of right-time marketing}

D. Goldstein and Yuchun Lee

DisCURSIVE. Journal of Database Marketing and Customer Strategy

Management (UK), Vol. 12, No. 3, p. 212 (14pp)

Claims that with the proliferation of new channels has come also a consumer backlash, evident in reduced response rates, privacy legislation and new technologies to impede marketing use of many channels. Quotes a survey to show consumers are afraid of companies providing information to others without permission, of insecure transactions and of hackers. Holds that a spillover from criminal activity to sloppy marketing is destroying consumer trust. Notes the fury over unwanted telephone solicitations, faxes and spam. Wonders what the response would be to a do-not-e-mail list. Lists (in an appendix) recent privacy legislation in both the USA and the EU. Records the growth of technology to block pop-up 


\section{Direct marketing, children, Electronic Communications Regulations, informed consent}

ads, prevent cookies, block phone calls from unknown numbers and filter e-mails - including blacklisting. Quotes AOL as saying that anti-spam filtering is blocking 1 billion pieces of spam daily. Claims that the top 12 ISPs incorrectly blocked or filtered 17 per cent of permission-based e-mail. Claims the answer is 'right-time marketing' - event-triggered campaigns which enormously improve response. Lists ten steps in moving to right-time marketing. Emphasises the necessity for data hygiene, and recommends the use of enterprise marketing management (EMM) suites which enable the integration of data from multiple touchpoints, systems and data sources.

Just as the abuse of all direct marketing channels has been more extreme in the USA than in Europe, so the backlash, now it is at last arriving, will be that much more severe. The recommendations are reasonable enough; whether they deserve the title of 'right-time marketing' is much more doubtful.

Research: $* \quad$ Practice: $* * \quad$ Originality: $* \quad$ Readability: $* * *$ Ref: 7208

\section{Direct marketing and children - How far can you go?}

N. Kouzeleas

LEGAL. Journal of Database Marketing and Customer Strategy

Management (UK), Vol. 12, No. 3, p. 257 (9pp)

Asks whether companies can send direct marketing material to children, and finds that there is no legal provision on this subject in the UK (although there is in the USA). Refers first to the Electronic Communications Regulations of 2003, with their 'opt-in' provisions in respect of electronic communications: these provisions apply to persons of all ages. Asks whether children can validly opt in, or from what age, and remarks that this depends upon the notion of 'informed consent'. Gives a variety of definitions by different parties of a 'child', a 'minor', a 'young person'; plumps for the DMA's best practice guideline, which holds that a child over 14 can give informed consent, but those under that age should have parental consent. Discusses difficulties of knowing/ discovering a child's age. Analyses the 'soft opt-in' provisions of the 2003 Regulations, and how these are interpreted by the Information Commissioner. Discusses methods of obtaining an opt-in, and the question of the time period for which it may be considered valid. Notes that minors under 18 cannot enter into a legal contract, and the potential consequences for marketers. Notes the danger in buying e-mail lists where permissions for communication may not have been obtained; advises acquiring a warranty from the seller. Advises keeping in touch with updates from the Commissioner, the DMA and the CAP.

The author is mistaken in alleging that the opt-in requirements of the 2003 Regulations apply to telephone, fax and iTV - they do not. In all other respects this is a useful round-up of some of the implications of the Regulations which apply to electronic mail (e-mail and SMS) - 
Financial services, internet, Europe
Brands, loyalty, differentiation especially for those who might be communicating with children. A full and clear account of all the Regulations may be found on www.informationcommissioner.gov.uk.

Research: * Practice: $* * \quad$ Originality: $* * * *$ Readability: $* * *$ Ref: 7209

\section{Digital finance in Europe: Competitive dynamics and online behaviour}

P. Barbesino, R. Camerani and A. Gaudino

RESEARCH. Journal of Financial Services Marketing (UK), Vol. 9, No. 3, p. 329 (15pp)

Notes a gap between banks' official data and figures of actual use of online services. Details survey methods of obtaining data. Gives table of number of internet users in five countries (Germany, the UK, Italy, France, Spain), and table showing number of users of financial websites (both financial information and online banking websites) in each country, and the percentage of total online users this represents. Notes that in each country, as the number of online banking users goes up, the number of users of financial information websites goes down. Remarks that a panEuropean banking market has not yet developed (despite some crossborder ventures). Notes the effort of retail banks to migrate their customers online, and the importance of a branch network in achieving this. States that internet users are smarter and less loyal than traditional customers, and that competition in the industry aims at share of wallet rather than market share. Claims that the potential for acquiring new customers online throughout Europe is immense. Concludes with a more detailed analysis on the online banking market in Italy and Spain, as 'emerging' markets.

Of some interest, not only in regard to financial services, but as a study of growing internet usage.

Research: $* * *$ Practice: $* * \quad$ Originality $* * \quad$ Readability: $* *$ Ref: 7210

The brand loyalty life cycle: Implications for marketers

R. Bennett and S. Rundle-Thiele

THEORETICAL. Journal of Brand Management (UK), Vol. 12, No. 4, p. 250 (14pp)

Looks at the history, or life cycle, of brand loyalty, which is described as falling into five eras: birth of brand loyalty (from 1870); a golden age (from 1915); a latent period (from 1930); the birth of multi-brand loyalty (from 1945); the decline of loyalty (from 1971 to the present). Gives a table showing the characteristics and the implications of each era. Discusses each in turn. Holds that the original purpose of brands was to provide a guarantee of consistent quality, which provided the element of differentiation; that differentiation through quality only works until the 


\section{Process engineering, outsourcing, standards, software}

product and its competition are providing as much quality as the market requires; thereafter differentiation shifts first to reliability, followed by convenience; in the final phase of competition it depends on either price or the provision of other benefits. Claims that customers loyal to one brand rarely make up more than 20 per cent of buyers, and that they tend to buy less than multi-brand loyalists. Holds that, contrary to some predictions, the decline of loyalty can be reversed by persuading consumers to connect with brands at an emotional or symbolic level. Instances Jeep and HarleyDavidson. Advocates the creation of brand communities.

This piece is a little long-winded and repetitive, but it is an easy read and gives a very convincing historical overview of brand loyalty and why things in this area are the way they are.

Research: ** Practice: $* * *$ Originality: $* * * *$ Readability: $* * * *$ Ref: 7211

\section{The coming commoditization of processes}

\section{T. H. Davenport}

THEORETICAL. Harvard Business Review (USA), June 2005, p. 101 (8pp)

Claims that increasingly business processes are being analysed, standardised and quality checked, and that this leads to greater opportunities for outsourcing of non-core activities. Notes that, despite the growing trend, most companies still perform most processes in-house. Points out the difficulty of assessing the quality offered by an external supplier, and claims that this can be overcome by the application of three types of process standards: process activity and flow standards, with particular reference to the SCOR model; process performance standards, leading to performance benchmarking; and process management standards. Claims that this last is the furthest advanced, since it does not require a consensus on process activities and flows. Illustrates by reference to the Software Engineering Institute's capability maturity model (CMM) which has become a worldwide standard for measuring a firm's software development capability, thus encouraging the growth of offshore software providers in India and China. Reckons the development of standards such as this will lead to an explosion of outsourcing and rapid commoditisation of processes, with consequent dramatic price reductions.

This thesis should be taken with a large pinch of salt, but no doubt it describes accurately enough the current trend (fad?) in the marketplace.

Research: $* * \quad$ Practice: $* * \quad$ Originality: $* * \quad$ Readability: $* *$ Ref: 7212

\section{Competent jerks, lovable fools and the formation of social networks}

T. Casciaro and M. S. Lobo

SURVEY. Harvard Business Review (USA), June 2005, p. 92 (8pp)

Notes that employees who require help in performing a particular task may have to exercise choice in where to look for it. Holds that the 


\section{Social networks, competence, likeability}

\section{Country of origin, brand name, endorsement, ethnocentrism, Austria}

exercise of this choice is not a matter of organisational structures, but of informal social networks. Relates a study of four organisations in which employees were asked to rate all their colleagues for competence and likeability. Finds that most people, in choosing a colleague to work with or to seek advice or help from, will give greater weight to likeability than to competence. Notes the dangers of this - particularly in the tendency of working groups of like-minded people to form, which may result in a lack of innovative insights. Suggests that when people work only with those they like, they may have a good time but accomplish little.

An interesting look at social networks in the workplace.

Research: $* * \quad$ Practice: $* \quad$ Originality: $* * *$ Readability: $* * *$ Ref: 7213

\section{Celebrity and foreign brand name as moderators of country-of-origin effects}

P. Chao, G. Wührer and T. Werani

RESEARCH. International Journal of Advertising (UK), Vol. 24, No. 2, p. 173 (20pp)

Looks at the effect of country-of-origin (COO) markings on consumer attitudes towards, product evaluation of and intention to purchase a VCR in Austria, in conjunction with a German/English brand name and endorsement by a US celebrity or a non-US non-celebrity. Attempts to determine whether branding and celebrity endorsement can moderate the effects of $\mathrm{COO}$ outside the USA. Finds that $\mathrm{COO}$ has no effect on consumer attitude, but does affect product quality evaluation; $\mathrm{COO}$ affects purchase intention, but in fact the addition of a US celebrity, compared with a German/Austrian non-celebrity, has a negative effect on purchase intention. Speculates that this may be due to ethnocentrism. Shows that, with a Chinese COO, an English brand name does better than a German one, but that a German COO performs better still, whether the brand name is German or English. Concludes that a German COO carries great weight in Austria, but that a German brand name will not affect a poorly perceived $\mathrm{COO}$.

This study can clearly not be transferred directly to other countries, but does raise some interesting questions for investigation.

Research: **** Practice:- Originality: $* *$ _ Readability: $* * *$ Ref: 7214

\section{Exploring the effectiveness of taxis as an advertising medium}

C. Veloutsou and C. O'Donnell

RESEARCH. International Journal of Advertising (UK), Vol. 24, No. 2, p. 217 (23pp)

Notes that systematic discussion and research into the use of advertising media has mostly concentrated on traditional media, plus the internet. Notes that outdoor advertising accounted in 2001 for 5 per cent of all 
Recession, proactive marketing advertising expenditure, and growing; of this, 'transit' advertising is a sub-set, making up 30 per cent of all UK outdoor advertising. Notes that taxi advertising can be both internal and external; focuses on the latter. Sets out to determine, through 425 questionnaires in Glasgow, Edinburgh and rural Ayrshire, the degree of exposure to different outdoor media, and the effectiveness of taxi advertising in particular. Finds that outdoor advertising has a broad reach, with taxis occupying a mid-place among outdoor media; that ads on taxis do not cause annoyance; that ads on taxis have a lower conscious recall than print media; that taxi ads are more effective in an urban than a rural environment; that taxi advertising, with short uncomplicated messages, has potential as a secondary or reinforcing medium. Concludes with remarks on limitations of the survey, and suggestions for future research.

An interesting look at an increasingly used but still under-researched advertising medium.

Research: $* * *$ Practice: $* *$ Originality: $* * *$ Readability: $* *$ Ref: 7215

\section{Turn adversity into advantage: Does proactive marketing during a recession pay off?}

R. Srinivasan, A. Rangaswamy and G. L. Lilien

SURVEY. International Journal of Research in Marketing (UK), Vol. 22, No. 2, p. 109 (17pp)

Notes that some firms prosper or even grow in a recession. Gives historical examples of companies investing in a recession; quotes Dell, Microsoft, DeBeers and BMW as current/recent examples. Notes that in the USA recession occurs every six years or so. Defines proactive marketing in a recession as interpretation of the recession as an opportunity, and the development of a response to capitalise on it. Identifies four factors as fundamental to a commitment to proactive marketing: a strategic emphasis on marketing; an entrepreneurial culture; availability of slack resources; the severity of the recession. Details a series of interviews with 20 senior marketing executives in 12 organisations across eight industries, together with 154 mailed survey forms. Finds that, as hypothesised, strategic emphasis on marketing, an entrepreneurial culture and the possession of slack resources each correlated positively with a drive to proactive marketing in a recession moderated by the severity of the recession - and that proactive marketing in a recession correlated positively with business performance both during and after the recession.

Do not pay too much attention to the details of the survey, or to the academic/mathematical gobbledegook surrounding it: the theme is a common-sense one, and worth taking on board.

Research: $* * *$ Practice: $* * *$ Originality: $* *$ Readability: $* *$ Ref: 7216 


\section{Affiliate marketing, commission, pay-for- performance}

\section{Affiliate marketing and its impact on e-commerce}

D. L. Duffy

EXPLANATORY. Journal of Consumer Marketing (UK), Vol. 22, No. 3, p. $161(3 p p)$

Claims that affiliate marketing represents the ultimate in pay-forperformance marketing, being a win-win relationship for both parties involved; that it is likely to become the mainstream e-commerce marketing strategy for the future. Explains the principles of affiliate marketing in familiar, offline terms: the affiliate assumes the cost and risk of marketing the advertiser's product in return for a commission on sales achieved by him. Then places this scenario in a web context: affiliates drive consumers (via ads, product links etc on their own websites) to the advertiser's website, via a network (three major examples named) which supports tracking, sales, calculation and payment of commission. Lists a number of well-known companies involved in either side of affiliate marketing. Criticises, for failure to deliver, early online marketing - eg pay per impression, pay per click and e-mail now floundering in spam.

There is no depth to this short introduction to affiliate marketing - but it is worth reading for those unfamiliar with the concept; its prognosis for this methodology is very likely correct.

Research: * Practice: $* * \quad$ Originality: * Readability: *** Ref: 7217

\section{Measuring risk-adjusted customer lifetime value and its impact on relationship marketing strategies and shareholder value}

L. Ryals and S. Knox

THEORETICAL, WITH EXAMPLE. European Journal of Marketing (UK), Vol. 39, Nos 5/6, p. 456 (14pp)

\section{CLTV, EV, risk} analysis
Asserts the purpose of business is to create and sustain mutually beneficial relationships with selected customers. Alleges 90 per cent of the UK's largest firms do not allocate marketing budget correctly: 80 per cent spend too much on customer acquisition and 10 per cent too much on retention. Efforts to balance acquisition/retention spend are based either on single-period customer profitability, or on forecasts of customer lifetime value (CLTV). Suggests that a more appropriate measure is shareholder value - the economic value (EV) of a customer, based on CLTV and adjusted for risk (to future revenue streams and to future cost of serving the customer). Gives details of a study of 12 key account business customers (with a full analysis of two of these) of a large insurance company, where each customer was assessed for CLTV, this then being risk adjusted to produce an EV. Comments on the different rankings of the 12 customers in relation to CLTV and EV. Concludes that retention activity should focus on customers with the highest CLTV, but that CLTV should be risk adjusted to produce EV.

Interesting, but the concept of performing customer-by-customer risk 
Loyalty, smart cards, RFID, biometrics

\section{RFID, barcoding, supply-chain management}

assessment is unlikely to be feasible outside of key account customers (as here) in a business-to-business environment.

Research: $* * * *$ Practice: $* * * *$ Originality: $* * *$ Readability: $* * *$ Ref: 7218

\section{Loyalty trends for the twenty-first century}

M. T. Caprizzi and R. Ferguson

THEORETICAL. Journal of Consumer Marketing (UK), Vol. 22, No. 2, p. $72(9 \mathrm{pp})$

Holds that loyalty programmes have now reached a stage of mid-life crisis: this is a mature market (particularly in the UK). Maintains, however, that this market is now poised for renewed creativity and growth. Identifies five key loyalty marketing trends, and discusses each in turn. Ubiquity: loyalty programmes are everywhere, with 89 million frequent-flyer adherents worldwide; gives numerous examples. Technology: discusses use of chip-based smart cards, which have never caught on in the USA but are widespread elsewhere. Gives positive international examples and one negative US example. Discusses RFID with examples of its use. Looks at biometrics, and early uses at Schiphol Airport, McDonalds, Prada in New York. Concludes that technology enables, but imagination wins. Coalition: notes the success of loyalty coalitions (eg Air Miles, Nectar) everywhere except in the USA and Mexico. Suggests coalitions based on lifestyles may be an answer. Customer analytics rule: lists analytical essentials. Wow! factor: notes the stunning sameness of renewals, leading to ennui. Gives examples of imaginative schemes. Suggests that failed schemes are not intrinsically wrong, but something is wrong with the offer, the approach or the administration.

This article misses the fundamental point that many (most?) successful loyalty schemes are no longer about retention (loyalty) at all, but about data capture, data mining and segmentation, leading to marketing relevance. All the same, this is a wide-ranging look at the dos and don'ts of such schemes.

Research: $* * * *$ Practice: $* * * *$ Originality: $* \quad$ Readability: $* * *$ Ref: 7219

\section{The benefits, challenges and impacts of radio frequency identification technology (RFID) for retailers in the UK P. Jones, C. Clarke-Hill, D. Hillier and D. Comfort \\ EXPLANATORY. Marketing Intelligence and Planning (UK), Vol. 23, No. 4, p. 395 (8pp)}

Outlines the characteristics and origins of RFID as a system to replace barcoding with a tamper-proof tag that can hold data which can be read electronically from a (short) distance and through obstacles. Notes a variety of international uses in the last 20 years - collecting road 
tolls, stacking air freight or cars on an assembly line. Notes retailer interest - especially Wal-Mart's demand that its large suppliers use tags (at their own cost); mentions early steps by Tesco, M\&S, Sainsbury and others. Notes a European grouping of retailers to identify and share RFID best practice. Discusses use of RFID at three levels: pallets, cases and items. Initial use so far has been up the supply chain, on pallets and cases, with impact on efficiency of supplychain management. Notes sundry benefits in warehousing, tracking, origin identification, etc and range of cost reductions. Notes the potential value of RFID at an item level in controlling shrinkage and reducing check-out times - but points to cost as a major factor. Asserts tag costs are reducing — but in high-volume low-margin stores could be prohibitive. Emphasises need to adapt systems to use flood of data. Notes need for agreed standard protocols, now being addressed. Notes privacy concerns.

An excellent account of this new technology, which thankfully avoids the science-fiction approach of much recent comment. The implications for marketers are only touched on, and merit close thought.

Research: $* * \quad$ Practice: $* * * *$ Originality: $* \quad$ Readability: $* * * * *$ Ref: 7220

\section{RFID, airlines, baggage handling, Delta}

\section{Where is my suitcase? RFID and airline customer service}

D. C. Wyld, M. A. Jones and J. W. Totten

CASE STUDY. Marketing Intelligence and Planning (UK), Vol. 23, No. 4, p. 382 (13pp)

Looks at airlines' baggage-handling problems, using current barcoding systems: asserts this technology works in $80-90$ per cent of cases at very best. Notes that customer perception of airline quality of service rests first on timeliness of flights and second on accurate baggage handling, and that satisfaction with airline performance has been declining since 1990. Notes the growing awareness in the airline industry of the potential of RFID to change this situation for the better. Describes the nature of RFID, and summarises its advantages over barcoding. Describes the case of Delta Airlines, now bottom of the major US airlines in customer perception, and with more than 12 mishandled bags per 1,000 customers. Reports Delta's pilot study of RFID, giving accurate readings of 95-99 per cent compared with 80-85 per cent with barcoding. Notes current tag cost of 25 cents, forecast to drop to five cents. Notes other minor problems; reports Delta's expectation of 60 per cent improvement in handling efficiency. Considers international implications.

This application is likely to be the first mass market (overall 2 billion baggage items annually) for RFID technology, which should bring costs tumbling.

Research: $* * *$ Practice: $* *$ Originality: $* *$ Readability: $* * *$ Ref: 7221 


\section{Australia, South Pacific, France, nuclear testing, boycotts}

\author{
Marketing \\ communications, \\ internet, service \\ companies
}

\section{The fallout from French nuclear testing in the South Pacific}

R. Ettenson and J. G. Klein

RESEARCH. International Marketing Review (UK), Vol. 22, No. 2, p. 200 (25pp)

Notes the level of uncertainty endemic in customer protest behaviour (especially boycotts) over events external to the firm(s) involved. Notes that the number of organised boycotts increased from 300 to 800 between 1990 and 1997; refers to four relevant websites. Notes a lack of crisis management plans in companies to deal with boycott situations, and the detrimental effect of boycotts on various aspects of firms' activities, including internal morale. Distinguishes instrumental (ie intended to achieve a specific object) and expressive (ie fuelled by animosity) boycotts; also direct (aimed at a firm) and indirect (eg aimed at a government) boycotts. Notes that France's nuclear testing in the South Pacific in 1995 resulted in an indirect boycott of perceived French products in Australia, New Zealand, Japan, South Korea. Examines, by a study of several hundred Australian consumers in late 1995, the effect of animosity in affecting consumers' willingness to buy French products, and their judgment of French product quality. Relates the findings of a second study, one year after cessation of French nuclear testing. Concludes that initially great animosity towards France resulted in a wide refusal to buy French goods, without affecting judgment of quality; the second study showed animosity continuing, at a reduced level — but indicated this time a connection with a denigration of French product quality.

An instructive example of the impact that external events can have without warning; prevention is impossible, but sound crisis planning may help.

Research: $* * *$ Practice: $* \quad$ Originality: $* * \quad$ Readability: $* * *$ Ref: 7222

\section{Effects of the internet on the marketing communication of service companies}

S. Lagrosen

SURVEY. Journal of Services Marketing (UK), Vol. 19, No. 2, p. 63 (7pp)

Seeks to examine how the internet is used for marketing communications by traditional service companies, and particularly how it has affected their use of other marketing channels. Gives details of a survey of 19 service companies in Sweden, conducted through 33 in-depth interviews. Lists the companies and their sectors. Reports the qualitative findings of the survey under a series of headings: the value of online marketing communication; the extent of online marketing communication (this varies from the case of one bank which aimed to be the internet leader in its sector, to another where online communication is controlled in separate branch offices); centralisation versus decentralisation; collaboration with external organisations; use of measurements; effect on other communication tools. Notes the need for integration of channels. 
Defines three main online communication strategies: personalised relationship strategy (which is the only real choice for small service companies); mass transaction strategy; mass relationship strategy. Suggests that a mass transaction strategy should be coupled with cost leadership.

Quite touching to find an author who accepts there is an alternative viable strategy to one of customer relationship management.

Research: $* * \quad$ Practice: $* \quad$ Originality: $* * \quad$ Readability: $* *$ Ref: 7223 